\title{
Dreaming as a story-telling instinct
}

\section{Edward F. Pace-Schott*}

Department of Psychiatry, Harvard Medical School and Massachusetts General Hospital, Charlestown, MA, USA

${ }^{*}$ Correspondence: epace-schott@partners.org

Edited by:

Jennifer M. Windt, Johannes Gutenberg-University of Mainz, Germany

Reviewed by:

Jennifer M. Windt, Johannes Gutenberg-University of Mainz, Germany

Dreams create new stories out of nothing. Although dreams contain themes, concerns, dream figures, objects, etc. that correspond closely to waking life, these are only story elements. The story itself weaves these mnemonic items together in a manner far more novel than a simple assemblage or collage, producing an experience having a life-like timeframe and life-like (if often bizarre and impossible) causality (Pace-Schott, 2007; Hobson, 2009). It is as if one is immersed in another "reality" entirely of one's own non-volitional, making (see Rechtschaffen, 1978). Given this phenomenology, it's not difficult to see why some indigenous animist societies believe dreams represent a separate world parallel with waking life (Nielsen, 1991). But neuroscience offers some other explanations.

Recent speculations have focused on the brain's "default network" as a possible neural substrate of dreaming (Pace-Schott, 2007, 2011a,b; Nir and Tononi, 2010; Wamsley and Stickgold, 2010; Domhoff, 2011). The default network consists of regions that, in the absence of exteroceptive attention or narrowly focused mental effort, support self-directed concerns, immersion in one's inner life (e.g., daydreaming) or imagining the inner life of others (Theory of Mind) (Buckner et al., 2008; Andrews-Hanna, 2012; Buckner, 2012). Most importantly for the current topic, the default network also simulates future scenarios and re-creates past ones drawing upon material in episodic, autobiographical, and semantic memory (Schacter et al., 2007; Schacter, 2012). Here I will suggest that such constructive activities of the brain represent a "hardwired" tendency to represent reality in the form of narrative-a "story-telling" instinct or module.

The default network was originally identified using positron emission tomography (PET) as those regions showing task-induced deactivation (Gusnard et al., 2001; Raichle et al., 2001). Subsequently, it was discovered that temporal synchrony of low frequency $(0.01-0.1 \mathrm{~Hz})$ spontaneous fluctuations of the blood-oxygen dependent (BOLD) signal of fMRI identifies both anatomical and functional connectivity among regions of the default network (Fox and Raichle, 2007; Greicius et al., 2008). This network consists of (1) medial parietal areas: posterior cingulate (pCC) and retrosplenial (Rsp) cortices; (2) posterior-lateral areas: inferior parietal lobule (IPL), temporoparietal junction (TPJ), lateral temporal cortex (LTC), temporal poles (TP); (3) medial temporal regions: hippocampal formation (HF), parahippocampal cortex (PHC); and (4) medial prefrontal areas: ventromedial (vmPFC) and dorsomedial (dmPFC) prefrontal cortices (Buckner et al., 2008; Spreng et al., 2009; Andrews-Hanna, 2012).

Resting state functional connectivity analyses of BOLD oscillations in waking have identified two default-network subsystems each of which fluctuates synchronously with central nodes in the pCC and anterior medial PFC (amPFC) but not with each other (Buckner et al., 2008; Andrews-Hanna et al., 2010; AndrewsHanna, 2012). The dorsomedial prefrontal subsystem includes the dmPFC, LTC, TPJ, and TP whereas the medial temporal lobe subsystem includes the HF, PHC, Rsp, IPL, and vmPFC. The dorsomedial prefrontal subsystem selectively activates during experimental tasks involving reflection on one's own mental state and that of others as well as other forms of social cognition (Andrews-Hanna et al., 2010; Mar, 2011; Andrews-Hanna, 2012). In contrast, the medial temporal lobe subsystem is selectively activated by retrieval of episodic and autobiographical memories as well as by imagination of future scenarios and concerns (Schacter et al., 2007; AndrewsHanna et al., 2010; Andrews-Hanna, 2012; Schacter, 2012). The central nodes activate along with most tasks that recruit one or the other subsystem (Andrews-Hanna, 2012).

Synchrony of BOLD fluctuations among components of the default network persists into light (Drummond et al., 2005; Horovitz et al., 2008; Larson-Prior et al., 2009) and Stage 2 (Laufs et al., 2007) NREM sleep. However, in slowwave sleep (SWS), frontal regions may uncouple from the rest of the default network (Horovitz et al., 2009; Samann et al., 2011, but see Koike et al., 2011). In the one study examining REM, unlike both waking and NREM, there appeared a lack of connectivity between the dorsomedial prefrontal subsystem and the posterior central node of the default network in the pCC (Koike et al., 2011). Koike et al. speculate that this disconnection contributes to the illogic and bizarreness of dream cognition, as has also been suggested for loss of antero-posterior EEG synchrony in the fast, gamma $(>30 \mathrm{~Hz})$ frequencies during REM (Corsi-Cabrera et al., 2003, 2008).

Earlier PET and fMRI activational studies of sleep also showed distinctly different activity in medial limbic versus lateral association cortex during REM sleep. After sleep onset during NREM, widespread cortical and subcortical areas become less active (Braun et al., 1997; Maquet et al., 1997; Nofzinger et al., 2002; Kaufmann et al., 2006). However, with the onset of REM sleep, midline limbic regions of the frontal cortex and subcortex reactivate to levels equaling and sometimes exceeding those of waking, whereas lateral and posterior-medial cortical areas remain in a NREM-like deactivated state (Maquet et al., 1996, 2005; Braun et al., 1997, 
1998; Nofzinger et al., 1997, 2004). This unique pattern of REM activation has been extensively mapped onto dream experiences (Hobson et al., 2000; Hobson and Pace-Schott, 2002; Hobson, 2009; PaceSchott, 2011a). NREM dreams may arise from more transient activations of similar networks (see Nielsen, 2000). Abnormally intensified dreaming, such as nightmares (Levin and Nielsen, 2007), or loss of dreaming (Solms, 1997) may represent, respectively, a failure to regulate or support operation of this limbic network.

Therefore, based on activational studies, the anterior central node (amPFC) and much of the mediotemporal subsystem (e.g., vmPFC, HF, PHC) of the default network may be similarly active in waking and REM. However, the posterior key node (pCC) and certain components of both the dorsomedial prefrontal (TPJ, LTL) and mediotemporal (Rsp, IPL) subsystems may not become similarly active. The one functional connectivity study of REM also suggests this disconnection between the pCC and dmPFC. Therefore, during REM-sleep dreaming, simulation of lifelike scenarios may occur but be incompletely constrained by autobiographical memory (both functions of the mediotemporal subsystem). Similarly, in comparison to resting-state waking, self-referential and social cognitive reasoning subserved by the dorsomedial prefrontal system may be less integrated with autobiographical memory.

But do dreams actually tell stories? Cipolli and Poli (1992) applied a formal, story grammar developed to describe narrative texts (Mandler and Johnson, 1977) to REM-dream reports collected by instrumental laboratory awakenings. Formal elements of dream narratives resembled typical stories, for example, by inclusion of characters, settings and a hierarchical event structure (Cipolli and Poli, 1992). Moreover, these elements remained stable between the nocturnal report and its retrospective morning report suggesting that story-like structure was a feature of the dream experience itself rather than being imposed upon its recall during waking. Cippolli and Poli suggest that higher-order cognitive processes organize dream experience (Cipolli et al., 1998). However, story structure may also be the basic manner in which brain organizes experience. Although obscured by temporal progression of events and of cause and effect in waking, this tendency may become more apparent during the non-volitional process of dreaming and pathological states such as delirium or confabulation (Solms, 1997; Hobson, 1999; Schnider, 2003, 2008; Hirstein, 2005).

Like dreaming, spontaneous behavioral confabulation involves a fictive narrative produced effortlessly, without insight as to its veracity, that is often acted upon by the patient (Schnider, 2003, 2008; Hirstein, 2005; Gilboa et al., 2006; Nahum et al., 2012). Spontaneous confabulation results from lesions of the anterior limbic system including posterior medial orbitofrontal cortex (pmOPFC, part of vmPFC) and its subcortical connections (Schnider, 2003, 2008; Hirstein, 2005; Gilboa et al., 2006). Confabulated memories usually contain real autobiographical events including those from the remote past (Schnider, 2003, 2008; Hirstein, 2005). Such loss of insight has been attributed to disruption of a reality filtering function localized to the vmPFC/pmOPFC (Schnider, 2003,2008 ) or to a more general deficit in strategic retrieval and verification of memories (Gilboa et al., 2006). In either case, however, phenomenological similarities exist with dreaming. For example, confabulators create plausible but false explanations for inconsistencies in their stories (Hirstein, 2005), closely resembling "ad-hoc explanations" for improbable dream occurrences (Williams et al., 1992). Additionally, "pathological false recognition" (Hirstein, 2005) in confabulation parallels dreamers' assigning an identity to dream characters perceptually dissimilar to their waking counterpart (Kahn et al., 2000).

Therefore, in both confabulation and dreaming, altered functioning of the prefrontal cortex may release from realityfiltering or executive constraint an innate human tendency to create stories that organize past, present, and future reality. Dreaming may represent a potent, naturally occurring form of confabulation in which imaginary events are not only created and believed but are vividly experienced as organized, multimodal hallucinations (Hobson, 1999; Pace-Schott, 2007, 2011a). Of course, hallucinosis differentiates dreaming and confabulation as does the fact that vmPFC/pmOPFC damage leads to confabulation whereas its activation accompanies dreaming. Nonetheless, in both phenomena, involuntary generation of an organized, fictive narrative entirely lacking insight suggests that they may share neural mechanisms. Possibly, the loss of pre-frontally mediated reality monitoring, due either to pmOPFC damage in confabulation or lateral frontal inactivity during dreaming, may release narrative-production mechanisms from inhibitory restraint.

But what about normal narrative production? Braun et al. (2001) performed PET conjunction analysis to identify modality-independent regions activated by storytelling in both English and American Sign Language. Although activity was shared in widespread medial and lateral cortical areas, medial prefrontal activation could be most directly related to the generic production of narrative discourse apart from the imagery, lexical, and memory processes shared by the two modes of storytelling (Braun et al., 2001). Therefore, portions of this same network may be engaged in volitional storytelling (see Mar, 2004 for review).

However, this putative storytelling module expressed as dreaming or confabulation rarely yields levels of organization equal to volitional narrative. For example, discontinuities in dream plots are sufficiently common that judges are unable to distinguish artificial reports created by splicing together text from different dreamers' reports from intact dreams (Stickgold et al., 1994). Nonetheless, the brain may attempt to impose wake-like temporal causality on any experience, real, or imagined. Dream hallucinosis itself may generate low-level narrative coherence by associative processes in which images evoke related images (see Rittenhouse et al., 1994) that are successively woven together by this putative tendency to organize experience as a story (Pace-Schott, 2005). In dreaming, diminished capacity for working memory, due to lateral prefrontal inactivity, may prevent reflection upon immediately past events leading to an unquestioned, forward progression of the plot as well as frequent narrative divergence. Interestingly, recent studies of lucid dreaming have shown both return of wake-like, gamma-frequency activity in 
the lateral PFC (Voss et al., 2009) and reactivation of portions of posterior default network along with lateral parietal, prefrontal, and occipito-temporal regions (Dresler et al., 2012).

So what might this storytelling module operating during dreams suggest to individuals wholly unfamiliar with neuroscience and scientific psychology? A keen interest in dreams among some huntergatherer societies is exemplified by the practice of dream sharing (Wax, 2004). Dreams are sometimes recounted as experiences from another, parallel existence. For example, The Amazonian Ese Eja believe that, during dreaming, their spirit inhabits a parallel world populated by other spirits, including those of animals (Peluso, 2004). Similarly, the Amazonian Mehinaku believe each individual contains several types of souls distinct from their waking selves, one of which, the "eye soul," is active during the night experiencing dreams but sleeps during the day (Gregor, 1981). Similarly, among the Andamanese Ongee society, discussion of sensory details from multiple individuals' dreams is used to build consensus as to the probable locations of seasonal food sources (Pandya, 2004). Therefore, recalled dreams provide a ready source of story-like narrative that can acquire cultural significance equal to or exceeding the retelling of waking events.

Basic human storytelling tendencies are widely postulated (e.g., Schechtman, 1996; Nigam, 2012; Stafford, 2012). By providing a template into which any experience, real or imaginary, can be inserted, story-telling may be one way the brain has evolved to efficiently represent and record waking experience. Evolution may have subsequently exploited this capacity for multifold purposes including future simulation. Hobson's (2009) protoconsciousness theory, describes how dreams adaptively support waking consciousness. Similarly, evolution may have exploited dreamed scenarios to rehearse survival strategies (Revonsuo, 2000). In indigenous societies, story-like structure may have facilitated integration of dream phenomena such as parasomnias (e.g., sleep paralysis, see Cheyne, 2003), lucidity, partial awakenings and dream bizarreness into existing belief systems, or even to create new beliefs and legends (see Nielsen, 1991).

\section{ACKNOWLEDGMENTS}

NIMH R21MH090357. Thanks to Deirdre Barrett, Ph.D. for helpful suggestions.

\section{REFERENCES}

Andrews-Hanna, J. R. (2012). The brain's default network and its adaptive role in internal mentation. Neuroscientist 18, 251-270.

Andrews-Hanna, J. R., Reidler, J. S., Sepulcre, J., Poulin, R., and Buckner, R. L. (2010). Functionalanatomic fractionation of the brain's default network. Neuron 65, 550-562.

Braun, A. R., Balkin, T. J., Wesenten, N. J., Carson, R. E., Varga, M., Baldwin, P., et al. (1997). Regional cerebral blood flow throughout the sleepwake cycle. An H2O PET study. Brain 120(Pt 7), 1173-1197.

Braun, A. R., Balkin, T. J., Wesensten, N. J., Gwadry, F., Carson, R. E., Varga, M., et al. (1998). Dissociated pattern of activity in visual cortices and their projections during human rapid eye movement sleep. Science 279, 91-95.

Braun, A. R., Guillemin, A., Hosey, L., and Varga, M. (2001). The neural organization of discourse: an H2 15O-PET study of narrative production in English and American sign language. Brain 124, 2028-2044.

Buckner, R. L. (2012). The serendipitous discovery of the brain's default network. Neuroimage 62, 1137-1145.

Buckner, R. L., Andrews-Hanna, J. R., and Schacter, D. L. (2008). The brain's default network: anatomy, function, and relevance to disease. Ann. N.Y. Acad. Sci. 1124, 1-38.

Cheyne, J. A. (2003). Sleep paralysis and the structure of waking-nightmare hallucinations. Dreaming 13, 163-179.

Cipolli, C., and Poli, D. (1992). Story structure in verbal reports of mental sleep experience after awakening in REM sleep. Sleep 15, 133-142.

Cipolli, C., Bolzani, R., and Tuozzi, G. (1998). Storylike organization of dream experience in different periods of REM sleep. J. Sleep Res. 7, 13-19.

Corsi-Cabrera, M., Guevara, M. A., and Del RioPortilla, Y. (2008). Brain activity and temporal coupling related to eye movements during REM sleep: EEG and MEG results. Brain Res. 1235, 82-91.

Corsi-Cabrera, M., Miro, E., Del-Rio-Portilla, Y., Perez-Garci, E., Villanueva, Y., and Guevara, M. A. (2003). Rapid eye movement sleep dreaming is characterized by uncoupled EEG activity between frontal and perceptual cortical regions. Brain Cogn. 51, 337-345.

Domhoff, G. W. (2011). The neural substrate for dreaming: is it a subsystem of the default network? Conscious. Cogn. 20, 1163-1174.

Dresler, M., Wehrle, R., Spoormaker, V. I., Koch, S. P., Holsboer, F., Steiger, A., et al. (2012). Neural correlates of dream lucidity obtained from contrasting lucid versus non-lucid REM sleep: a combined EEG/fMRI case study. Sleep 35, 1017-1020.

Drummond, S. P., Bischoff-Grethe, A., Dinges, D. F., Ayalon, L., Mednick, S. C., and Meloy, M. J. (2005). The neural basis of the psychomotor vigilance task. Sleep 28, 1059-1068.

Fox, M. D., and Raichle, M. E. (2007). Spontaneous fluctuations in brain activity observed with functional magnetic resonance imaging. Nat. Rev. Neurosci. 8, 700-711.

Gilboa, A., Alain, C., Stuss, D. T., Melo, B., Miller, S., and Moscovitch, M. (2006). Mechanisms of spontaneous confabulations: a strategic retrieval account. Brain 129, 1399-1414.

Gregor, T. (1981). "Far, far away my shadow wandered ... ": the dream symbolism and dream theories of the Mehinaku Indians of Brazil. Am. Ethnol. 8, 709-720.

Greicius, M. D., Supekar, K., Menon, V., and Dougherty, R. F. (2008). Resting-state functional connectivity reflects structural connectivity in the default mode network. Cereb. Cortex 19, 72-78.

Gusnard, D. A., Raichle, M. E., and Raichle, M. E. (2001). Searching for a baseline: functional imaging and the resting human brain. Nat. Rev. Neurosci. 2, 685-694.

Hirstein, W. (2005). Brain Fiction, Self Deception and the Riddle of Confabulation. Cambridge, MA: MIT Press.

Hobson, J. A. (1999). Dreaming as Delirium. Cambridge, MA: MIT Press.

Hobson, J. A. (2009). REM sleep and dreaming: towards a theory of protoconsciousness. Nat. Rev. Neurosci. 10, 803-813.

Hobson, J. A., and Pace-Schott, E. F. (2002). The cognitive neuroscience of sleep: neuronal systems, consciousness and learning. Nat. Rev. Neurosci. 3, 679-693.

Hobson, J. A., Pace-Schott, E. F., and Stickgold, R. (2000). Dreaming and the brain: toward a cognitive neuroscience of conscious states. Behav. Brain Sci. 23, 793-842. discussion: 904-1121.

Horovitz, S. G., Braun, A. R., Carr, W. S., Picchioni, D., Balkin, T. J., Fukunaga, M., et al. (2009) Decoupling of the brain's default mode network during deep sleep. Proc. Natl. Acad. Sci. U.S.A. 106, 11376-11381.

Horovitz, S. G., Fukunaga, M., De Zwart, J. A., Van Gelderen, P., Fulton, S. C., Balkin, T. J., et al. (2008). Low frequency BOLD fluctuations during resting wakefulness and light sleep: a simultaneous EEG-fMRI study. Hum. Brain Mapp. 29, 671-682.

Kahn, D., Stickgold, R., Pace-Schott, E. F., and Hobson, J. A. (2000). Dreaming and waking consciousness: a character recognition study. J. Sleep Res. 9, 317-325.

Kaufmann, C., Wehrle, R., Wetter, T. C., Holsboer, F., Auer, D. P., Pollmacher, T., et al. (2006). Brain activation and hypothalamic functional connectivity during human non-rapid eye movement sleep: an EEG/fMRI study. Brain 129, 655-667.

Koike, T., Kan, S., Misaki, M., and Miyauchi, S. (2011). Connectivity pattern changes in defaultmode network with deep non-REM and REM sleep. Neurosci. Res. 69, 322-330.

Larson-Prior, L. J., Zempel, J. M., Nolan, T. S., Prior, F. W., Snyder, A. Z., and Raichle, M. E. (2009). Cortical network functional connectivity in the descent to sleep. Proc. Natl. Acad. Sci. U.S.A. 106, 4489-4494.

Laufs, H., Walker, M. C., and Lund, T. E. (2007). 'Brain activation and hypothalamic functional connectivity during human non-rapid eye movement sleep: an EEG/fMRI study'-its limitations 
and an alternative approach. Brain 130, e75. author reply: e76.

Levin, R., and Nielsen, T. A. (2007). Disturbed dreaming, posttraumatic stress disorder, and affect distress: a review and neurocognitive model. Psychol. Bull. 133, 482-528.

Mandler, J. M., and Johnson, N. S. (1977). Remembrance ofthings parsed: story structure and recall. Cogn. Psychol. 9, 111-151.

Maquet, P., Degueldre, C., Delfiore, G., Aerts, J., Peters, J. M., Luxen, A., et al. (1997). Functional neuroanatomy of human slow wave sleep. J. Neurosci. 17, 2807-2812.

Maquet, P., Peters, J., Aerts, J., Delfiore, G., Degueldre, C., Luxen, A., et al. (1996). Functional neuroanatomy of human rapid-eye-movement sleep and dreaming. Nature 383, 163-166.

Maquet, P., Ruby, P., Maudoux, A., Albouy, G., Sterpenich, V., Dang-Vu, T., et al. (2005). Human cognition during REM sleep and the activity profile within frontal and parietal cortices: a reappraisal of functional neuroimaging data. Prog. Brain Res. 150, 219-227.

Mar, R. A. (2004). The neuropsychology of narrative: story comprehension, story production and their interrelation. Neuropsychologia 42, 1414-1434.

Mar, R. A. (2011). The neural bases of social cognition and story comprehension. Annu. Rev. Psychol. 62, 103-134.

Nahum, L., Bouzerda-Wahlen, A., Guggisberg, A., Ptak, R., and Schnider, A. (2012). Forms of confabulation: dissociations and associations. Neuropsychologia 50, 2524-2534.

Nielsen, T. A. (1991). "Reality dreams and their effects on spiritual belief: a revision of animism theory," in Dream Images: A Call to Mental Arms, eds J. Gackenbach and A. A. Sheikh (Amityville: Baywood Publishing), 233-264.

Nielsen, T. A. (2000). A review of mentation in REM and NREM sleep: "covert" REM sleep as a possible reconciliation of two opposing models. Behav. Brain Sci. 23, 851-866. discussion: 904-1121.

Nigam, S. (2012). The storytelling brain. Sci. Eng. Ethics 18, 567-571.

Nir, Y., and Tononi, G. (2010). Dreaming and the brain: from phenomenology to neurophysiology. Trends Cogn. Sci. 14, 88-100.

Nofzinger, E. A., Buysse, D. J., Germain, A., Carter, C., Luna, B., Price, J. C., et al. (2004). Increased activation of anterior paralimbic and executive cortex from waking to rapid eye movement sleep in depression. Arch. Gen. Psychiatry 61, 695-702.

Nofzinger, E. A., Buysse, D. J., Miewald, J. M., Meltzer, C. C., Price, J. C., Sembrat, R. C., et al. (2002).
Human regional cerebral glucose metabolism during non-rapid eye movement sleep in relation to waking. Brain 125, 1105-1115.

Nofzinger, E. A., Mintun, M. A., Wiseman, M., Kupfer, D. J., and Moore, R. Y. (1997). Forebrain activation in REM sleep: an FDG PET study. Brain Res. 770, 192-201.

Pace-Schott, E. F. (2005). Complex hallucinations in waking suggest mechanisms of dream construction, Commentary on: why people see things that are not there: a novel perception and attention deficit model for recurrent complex visual hallucinations by D. Collerton, E. Perry and I. McKeith. Behav. Brain Sci. 28, 771-772.

Pace-Schott, E. F. (2007). "The frontal lobes and dreaming," in The New Science of Dreaming, Vol. 1, eds D. Barrett and P. McNamara (Westport, CT: Praeger, Greenwood Press), 115-154.

Pace-Schott, E. F. (2011a). "The neurobiology of dreaming," in Principles and Practice of Sleep Medicine, 5th Edn., eds M. H. Kryger, T. Roth, and W. C. Dement (Philadelphia, PA: Elsevier), 563-575.

Pace-Schott, E. F. (2011b). "REM sleep and dreaming," in Rapid Eye Movement Sleep - Regulation and Function, eds B. N. Mallick, S. R. Pandi-Permual, R. W. McCarley, and A. R. Morrison (Cambridge: Cambridge University Press), 8-20.

Pandya, V. (2004). Forest smells and spider webs: ritualized dream interpretation among andaman islanders. Dreaming 14 , 136-150.

Peluso, D. M. (2004). "That which I dream Is true": dream narratives in an amazonian community. Dreaming 14, 107-119.

Raichle, M. E., Macleod, A. M., Snyder, A. Z., Powers, W. J., Gusnard, D. A., and Shulman, G. L. (2001). A default mode of brain function. Proc. Natl. Acad. Sci. U.S.A. 98, 676-682.

Rechtschaffen, A. (1978). The single-mindedness and isolation of dreams. Sleep 1, 97-109.

Revonsuo, A. (2000). The reinterpretation of dreams: an evolutionary hypothesis of the function of dreaming. Behav. Brain Sci. 23, 877-901. discussion: 904-1121.

Rittenhouse, C. D., Stickgold, R., and Hobson, J. A. (1994). Constraints on the transformation of characters and objects in dream reports. Conscious. Cogn. 3, 100-113.

Samann, P. G., Wehrle, R., Hoehn, D., Spoormaker, V. I., Peters, H., Tully, C., et al. (2011). Development of the brain's default mode network from wakefulness to slow wave sleep. Cereb. Cortex 21, 2082-2093.
Schacter, D. L. (2012). Constructive memory: past and future. Dialogues Clin. Neurosci. 14, 7-18.

Schacter, D. L., Addis, D. R., and Buckner, R. L. (2007). Remembering the past to imagine the future: the prospective brain. Nat. Rev. Neurosci. 8, 657-661.

Schechtman, M. (1996). The Constitution of Selves. Ithaca, NY: Cornell University Press.

Schnider, A. (2003). Spontaneous confabulation and the adaptation of thought to ongoing reality. Nat. Rev. Neurosci. 4, 662-671.

Schnider, A. (2008). The Confabulating Mind: How the Brain Creates Reality. Oxford: Oxford University Press.

Solms, M. (1997). The Neuropsychology of Dreams: A Clinico-Anatomical Study. Mahwah, NJ: Lawrence Erlbaum Associates.

Spreng, R. N., Mar, R. A., and Kim, A. S. (2009). The common neural basis of autobiographical memory, prospection, navigation, theory of mind, and the default mode: a quantitative meta-analysis. J. Cogn. Neurosci. 21, 489-510.

Stafford, T. (2012). The Narrative Escape. Milano: DigiPub, 40K Books.

Stickgold, R., Rittenhouse, C., and Hobson, J. A. (1994). Dream splicing: a new technique for assessing thematic coherence in subjective reports of mental activity. Conscious. Cogn. 3, 114-128.

Voss, U., Holzmann, R., Tuin, I., and Hobson, J. A. (2009). Lucid dreaming: a state of consciousness with features of both waking and non-lucid dreaming. Sleep 32, 1191-1200.

Wamsley, E. J., and Stickgold, R. (2010). Dreaming and offline memory processing. Curr. Biol. 20, R1010-R1013.

Wax, M. L. (2004). Dream sharing as social practice. Dreaming 14, 83-93.

Williams, J., Merritt, J., Rittenhouse, C., and Hobson, J. A. (1992). Bizarreness in dreams and fantasies: implications for the activation-synthesis hypothesis. Conscious. Cogn. 1, 172-185.

Received: 01 March 2013; accepted: 14 March 2013; published online: 02 April 2013.

Citation: Pace-Schott EF (2013) Dreaming as a storytelling instinct. Front. Psychol. 4:159. doi: 10.3389/fpsyg. 2013.00159

This article was submitted to Frontiers in Consciousness Research, a specialty of Frontiers in Psychology.

Copyright (c) 2013 Pace-Schott. This is an open-access article distributed under the terms of the Creative Commons Attribution License, which permits use, distribution and reproduction in other forums, provided the original authors and source are credited and subject to any copyright notices concerning any third-party graphics etc. 